\title{
LAMA MENDERITA ULKUS DENGAN DISTRESS DAN DEPRESI PADA PENDERITA DIABETES MELLITUS
}

\section{Long Time Suffered, Diabetic Ucler With Distress And Depression In Diabetes Mellitus}

\author{
Maulidta $\mathrm{K} \mathrm{W}^{1}$, Dyah Restuning $\mathrm{P}^{2}$, \\ Akademi Keperawatan Widya Husada Semarang, \\ Jl. Subali Raya No.12 Krapyak Semarang, \\ maulidtakw@gmail.com
}

\begin{abstract}
ABSTRAK
DM (Diabetes Mellitus) atau kencing manis merupakan salah satu jenis penyakit kronis, dimana kejadiannya semakin meningkat dari tahun ke tahun. Adanya kekhawatiran berlebih apabila penyakit yang diderita ternyata tidak kunjung sembuh menjadi faktor timbulnya distress dan depresi pada pasien diabetes mellitus. Lama sakit yang dialami pasien DM ditambah dengan adanya komplikasi ulkus diabetikum terjadinya penurunan kualitas kesehatan pasien DM. Penelitian ini bertujuan untuk mengetahui hubungan antara lama sakit dan adanya ulkus diabetikum dengan tingkat distress dan depresi pada pasien diabetes melitus di RSUD K.R.M.T Wongsonegoro. Penelitian ini adalah penelitian kuantitatif dengan metode deskriptif korelatif, dimana peneliti berusaha hubungan lama sakit dan adanya ulkus dengan tingkat distress dan depresi DM dengan pendekatan cross sectional. Populasi penelitian ini adalah pasien penderita diabetes mellitus di RSUD K.R.M.T Wongsonegoro. Sampel penelitian sebanyak 32 pasien yang diperoleh denganteknik accidental sampling. Pengumpulan data penelitian menggunakan kuesioner dananalisis data penelitian menggunakan uji korelasi product moment. Kesimpulanpenelitian adalah lama sakit pasien sebagian besar lebih dari 10 tahun, tingkat distress pasien sebagian besar adalah ringan, sedangkan komponen distress yang paling dominant terhadap timbulnya distres pasien adalah beban emosi dan respon terhadap tenaga kesehatan, dan terdapat hubungan antara lama sakit dan adanya ulkus dengan tingkat distress dan depresi pada pasien diabetes mellitus di RSUD K.R.M.T Wongsonegoro.
\end{abstract}

Kata Kunci : ulkus, Distress, depresi, Diabates Mellitus

\begin{abstract}
DM (Diabetes Mellitus) or diabetes is one type of chronic disease, where the incidence is increasing from year to year. Excessive worries if the illness is not cured is a factor in the occurrence of distress and depression in patients with diabetes mellitus. The duration of illness experienced by DM patients coupled with the presence of complications of diabetic ulcers decreases the quality of health of DM patients. This study aims to determine the relationship between the duration of illness and the presence of diabetic ulcers with the level of distress and depression in patients with diabetes mellitus in the RSUD K.R. Wongsonegoro Hospital. This research is a quantitative study with a correlative descriptive method, where the researcher seeks long association of pain and the presence of an ulcer with a degree of distress and depression in DM with a cross sectional approach. The population of this study was patients with diabetes
\end{abstract}


mellitus in the RSUD K.R.T. Wongsonegoro. The study sample was 32 patients obtained with the accidental sampling technique. Research data collection uses questionnaires and research data analysis using product moment correlation test. The conclusions are that the patient's illness duration is mostly more than 10 years, the level of distress of the patient is mostly mild, while the most dominant component of distress to the onset of patient distress is emotional burden and response to health workers, and there is a relationship between the duration of illness and the level of ulcer distress and depression in patients with diabetes mellitus in RSUD KRMT Wongsonegoro.

Keywords: ulcer, Distress, depression, Diabetes Mellitus

\section{PENDAHULUAN}

Diabetes Melitus (DM) atau kencing manis telah menjadi masalah kesehatan dunia dengan angka kejadian yang terus meningkat. Prevalensi DM di Indonesia menunjukkan angka yang sangat tinggi sehingga tindakan antisipasi dan penatalaksanaan yang tepat bagi penderita DM (Kusuma Dewi, 2009 dalam Subandiyo, et al. 2012). DM dapat menimbulkan beberapa komplikasi. Masalah kaki dengan ulkus merupakan masalah yang umum pada pasien dengan diabetes bahkan akhirnya dapat menyebabkan amputasi. Permasalahan pada kaki telah dilaporkan sebagai alasanalasan pasien perlu masuk ke rumah sakit. Menurut WHO lesi-lesi yang sering menyebabkan ulserasi dan rusaknya jaringan yang lebih dalam yang berkaitan yang berkaitan dengan gangguan neurolgis dan vaskular pada tungkai (Damayanti 2015).

Ketika seseorang menderita Diabetes Melitus, maka diharuskan menjalani beberapa pengobatan dan perubahan pola hidup. Perubahan dalam hidup yang mendadak membuat penderita Diabetes Melitus menunjukkan reaksi psikologis yang negatif diantaranya adalah marah, merasa tidak berguna, kecemasan yang meningkat, stres dan depresi. Menurut Piette, American Journal of Managed Care (dalam Setyani, 2012), depresi yang dialami penderita Diabetes dua kali lebih banyak di antara penduduk umumnya, dengan $15 \%$ sampai $30 \%$ dari pasien Diabetes yang memenuhi kriteria depresi. Penelitian akhir-akhir ini mendapatkan bahwa penderita Diabetes terutama yang mengalami komplikasi, mempunyai risiko depresi 3 kali lipat dibandingkan masyarakat umum. Komplikasi Diabetes dapat menyebabkan kehidupan sehari-hari yang lebih sulit sehingga menimbulkan kesedihan yang berkepanjangan (Soegondo, 2009). Di samping itu, Pusat Pengendalian Penyakit dan Pencegahan (CDC) menyebutkan bahwa Diabetes dapat menggandakan risiko seseorang mengalami depresi (Samiadi, 2016). Ada beberapa alasan mengapa hubungan Diabetes dan depresi itu penting. Salah satunya adalah gejala depresi membuat Diabetes lebih sulit dikelola. Depresi pada penderita Diabetes akan mempengaruhi pengobatan dan sulitnya mengubah pola hidup. Hal ini dikarenakan pasien Diabetes yang mengalami depresi akan cenderung mengalami kesedihan, tubuh menjadi lemah, berkurangnya nafsu makan dan minat dalam segala hal. Akibatnya akan mengalami kemajuan pengobatan yang lambat.

\section{BAHAN DAN METODE}

Jenis penelitian ini adalah kuantitatif observasional dengan rancangan penelitian cross-sectional, yaitu suatu penelitian untuk mempelajari dinamika korelasi antara lama menderita dan adanya ulkus DM dengan stress dan depresi pada diabetes mellitus, dengan cara pendekatan observasional atau 
pengumpulan data sekaligus pada suatu saat (point time approach) (Notoatmodjo, 2012). Subyek penelitian yaitu penderita Diabetes Mellitus yang dirawat di RSUD K.R.M.T Wongsonegoro yang terdiri dari 32 responden sebagai sampel penelitian. Teknik pemilihan responden dengan total sampling.
Penelitian dilakukan di RSUD K.R.M.T Wongsonegoro pada bulan Maret - Agustus 2018. Pengambilan data dilakukan dengan cara wawancara terhadap responden menggunakan instrumen berupa kuesioner DASS (Depresion Anxiety Stress Scale).

\section{HASIL DAN PEMBAHASAN}

Tabel 1 Karakteristik penderita Diabetes Mellitus

\begin{tabular}{|c|c|c|c|}
\hline \multirow{4}{*}{$\begin{array}{l}\text { No } \\
1 .\end{array}$} & Karakteristik & Frekuensi & Prosentase $(\%)$ \\
\hline & Umur Responden & & \\
\hline & a. $\quad 35-45$ tahun & 5 & 15,6 \\
\hline & b. $>45$ tahun & 27 & 84.4 \\
\hline \multirow[t]{2}{*}{2.} & Jenis Kelamin & & \\
\hline & Perempuan & 32 & 100 \\
\hline \multirow[t]{5}{*}{3.} & Tingkat Pendidikan & & \\
\hline & a. SD & 10 & 31 \\
\hline & b. SMP & 10 & 31 \\
\hline & c. SMA & 11 & 34 \\
\hline & d. $\quad$ PT & 1 & 4 \\
\hline \multirow[t]{2}{*}{4} & Pekerjaan & & \\
\hline & Ibu Rumah Tangga & 32 & 100 \\
\hline \multirow[t]{2}{*}{5} & Komplikasi & & \\
\hline & Ulkus Diabetik & 32 & 100 \\
\hline \multirow[t]{4}{*}{6} & Lama Sakit & & \\
\hline & $<5$ tahun & 7 & 21 \\
\hline & 5-10 tahun & 12 & 38 \\
\hline & $>10$ tahun & 13 & 41 \\
\hline
\end{tabular}

Sumber :data primer 2018

Karakteristik responden menurut umur menunjukkan sebagian besar berumur $>45$ tahun. Peningkatan umur menyebabkan seseorang beresiko terhadap peningkatan kejadian DM. Hal tersebut sebagaimana dikemukakan oleh Kekenusa, Ratag, \&Wuwungan (2013) bahwa terdapat hubungan antara umur dan riwayat hidup dengan kejadian DM tipe 2, dimana orang yang berumur lebih dari 45 tahun memiliki resiko menderita DM tipe 2 delapan kali lebih tinggi dibandingkan orang yang berusia dibawah 45 tahun. Hal ini karena penuaan memiliki hubungan yang erat dengan kejadian resistensi insulin sehingga kemampuan fungsi tubuh terhadap pengendalian glukosa darah yang tinggi kurang optimal (Suyono, 2007). Penelitian lain dilakukan Jelantik (2014) menyimpulkan bahwa terdapat hubungan faktor risiko umur dengan kejadian DM tipe 2 di wilayah Kerja Puskesmas Mataram tahun 2013 dimana sebagian besar berumur $>40$ tahun. Peningkatan diabetes risiko diabetes seiring dengan umur, khususnya pada usia lebih dari 40 tahun, disebabkan karena pada usia tersebut mulai terjadi peningkatan intolenransi glukosa. Adanya proses penuaan menyebabkan berkurangnya kemampuan sel $\beta$ pancreas dalam memproduksi insulin (Sunjaya, 2009). 
Karakteristik responden menurut jenis kelamin menunjukkan seluruh responden adalah perempuan. Prevalensi DM pada perempuan dibuktikan dalam penelitian Jelantik (2014), yaitu terdapat hubungan faktor risiko umur, jenis kelamin, kegemukan dan hipertensi dengan kejadian DM tipe 2 di wilayah Kerja Puskesmas Mataram Tahun 2013, dimana sebagian besar berjenis kelamin perempuan. Perempuan merupakan kelompok yang memiliki risiko penyakit DM lebih tinggi dibandingkan laki-laki. Hal ini karena selain proses hormonal, kemungkinan perempuan memiliki peluang DM yang lebih tinggi dibandingkan laki-laki karena pada perempuan kadar LDL atau kolesterol jahat trigliserida lebih tinggi dibandingkkan lakilaki. Penelitian lain dilakukan Trisnawati, Kurnia \& Setyorogo (2013) yang menunjukkan jenis kelamin berhubungan dengan kejadian DM Tipe 2 di Puskesmas Kecamatan Cengkareng. Wanita lebih berisiko mengidap diabetes karena secara fisik wanita memiliki peluang peningkatan indeks masa tubuh yang lebih besar. Sindroma siklus bulanan (premenstrual syndrome), pasca-menopouse yang membuat distribusi lemak tubuh menjadi mudah terakumulasi akibat proses hormonal tersebut sehingga wanita berisiko menderita diabetes mellitus tipe2 (Irawan, 2010).

Karakteristik responden menurut pendidikan menunjukkan distribusi tertinggi adalah SMA. Tingkat pendidikan seseorang berhubungan dengan kemampuan orang tersebut dalam menerjemahkan suatu informasi menjadi pengetahuan yang selanjutnya menjadi dasar dalam melakukan suatu tindakan. Hal ini sebagaimana dikemukkakan oleh Notoatmodjo (2012) yang menyatakan bahwa tingkat pendidikan seseorang berhubungan dengan kemampuan seseorang dalam menerima dan menerjemahkan informasi menjadi pengetahuan. Semakin tinggi tingkat pendidikan seseorang, maka semakin tinggi pula kemampuannya dalam menangkap suatu informasi. Tingkat pendidikan dapat meningkatkan pengetahuan tentang kesehatan. Pendidikan merupakan hal yang sangat penting dalam mempengaruhi pikiran seseorang. Seorang yang berpendidikan ketika menemui suatu masalah akan berusaha berfikir sebaik mungkin dalam menyelesaikan masalah tersebut. Orang yang berpendidikan baik cenderung akan mampu berfikir tenang terhadap suatu masalah (Perry \& Potter, 2005). Penelitian Galveia, Cruz \& Deep (2012) tentang pengaruh faktor demografis terhadap kepatuhan klien diabetes dalam pengelolaan stres, kecemasan dan distress menyimpulkan bahwa faktor pendidikan merupakan salah satu variabel yang memiliki hubungan secara signifikan dengan kepatuhan klien diabetes dalam pengelolaan stres, kecemasan dan distress.

Distribusi klien menurut pekerjaan menunjukkan seluruh responden adalah ibu rumah tangga. Banyak hal yang dapat dikaitkan dengan pekerjaan seseorang, dimulai dari segi pendapatan sampai dengan aktivitasfisik yang dilakukan selama bekerja. Aktivitas fisik yang dilakukan oleh ibu rumah tangga relatif tinggi mulai dari memasak, mencuci, membersihkan rumah dan lain sebagainya. Aktivitas fisik yang dilakukan oleh pasien DM dapat berfungsisebagai media untuk mengontrol kenaikan kadar gula darahnya. Hal inisebagaimana dikemukakan oleh Tjandra (2008) yang menyampaikanbahwa aktivitas fisik adalah semua gerakan tubuh yang membakar kalori,misalnya menyapu, naik turun tangga, menyeterika, berkebun danberolahraga.

Distribusi klien dengan kejadian ulkus diabetik menunjukkan seluruh responden mempunyai ulkus diabetik. Penelitian yang dilakukan oleh Ferawati (2014) menunjukkan bahwa terdapat hubungan 
yang bermakna antara neuropati sensorik dengan kejadian ulkus diabetikum $p=0,018$. Hasil penelitian lain yang dilakukan oleh Hastuti (2008) menunjukan lama menderita diabetes mellitus merupakan faktor terjadinya ulkus kaki yaitu lama menderita diabetes $\geq 10$ tahun memiliki resiko terjadinya ulkus kaki sebesar 6 kali lebih besar dibandingkan dengan $<5$ tahun. Hastuti (2008) menyatakan penderita Ulkus diabetika terutama terjadi pada penderita Diabetes mellitus yang telah menderita 10 tahun atau lebih apabila kadar glukosa darah tidak terkendali, karena akan muncul komplikasi berhubungan dengan vaskuler sehingga mengalami makroangiopatimikroangiopoti yang akan terjadi vaskulopati dan neuropati yang mengakibatkan menurunnya sirkulasi darah dan adanya robekan/luka pada kaki penderita diabetik yang sering tidak dirasakan. Smeltzer \& Bare (2013) menambahkan bahwa prevalensi neuropati meningkat bersamaan dengan pertambahan usia dan lamanya penyakit, sehingga peneliti menyimpulkan bahwa semakin lamanya seseorang didiagnosa diabetes melitus maka semakin berisiko terhadap terjadinya komplikasi sehingga apabila diabetes melitus tidak terkontrol dengan baik, maka kemungkinan terjadinya komplikasi berupa ulkus diabetikum dapat terjadi.

Distribusi frekuensi lama sakit responden menunjukkan distribusi tertinggi adalah lebih dari 10 tahun. Semakin lama sakit, maka proses perawatan juga lama, sehinga kemampuan pasien dalam menyesuaikan dirinya semakin baik. Lamanya menderita DM juga berpengaruh terhadap keyakinan klien dalam perawatan yang tentunya berpengaruh pada kualitas hidupnya. Klien yang telah menderita $\mathrm{DM} \geq$ 11 tahun memiliki efikasi diri yang baik daripada klien yang menderita DM $<10$ tahun, hal itu disebabkan karena klien telah berpengalaman dalam mengelola penyakitnya dan memiliki koping yang baik (Reid \& Walker, 2009).

Tabel 2 Hubungan Lama sakit dengan stress penderita Diabetes Mellitus

\begin{tabular}{|c|c|c|c|c|c|c|}
\hline \multirow{3}{*}{ Lama Sakit } & \multicolumn{4}{|c|}{ Tingkat stress } & \multirow{3}{*}{$\mathrm{P}$ value } & \multirow{3}{*}{$\mathrm{P}$ hitung } \\
\hline & \multicolumn{2}{|c|}{ Ringan } & & & & \\
\hline & $\mathrm{f}$ & & $\mathrm{F}$ & $\%$ & & \\
\hline$<5$ tahun & 6 & 0.001 & 2 & 25 & 0.001 & $-0,674$ \\
\hline 5-10 tahun & 13 & & 1 & 8 & & \\
\hline$>10$ tahun & 13 & 100 & 0 & 0 & & \\
\hline Total & 29 & 90 & 3 & 10 & & \\
\hline
\end{tabular}

Sumber :data primer 2018

Tabulasi silang hubungan lama sakit dengan tingkat distress menunjukkan pada responden dengan lama sakit kurang dari 5 tahun sebagian besar memiliki tingkat distress yang ringan yaitu sebanyak 6 responden dan berat sebanyak 2 responden. Pada responden dengan lama sakit 5-10 tahun terdapat 13 responden yang memiliki tingkat distress ringan dan 1 responden yang memiliki tingkat distress berat. Sedangkan pada responden dengan lama sakit lebih dari 10 tahun semuanya atau 13 responden
$(100 \%)$ memiliki tingkat distress yang ringan. Berdasarkan tabulasi tersebut menunjukkan bahwa semakin lama sakit maka tingkat distressnya semakin ringan.

Hasil uji korelasi product moment diperoleh nilai $\mathrm{r}_{\text {hitung }}$ sebesar -0,674 dengan tingkat signifikansi (p-value) 0,001. Nilai signifikansi uji (p-value) lebih kecil dari $0,05(0,001<0,05)$ maka keputusan uji adalah $\mathrm{H}_{0}$ ditolak yang bermakna bahwa hipotesis penelitian yang menyatakan ada hubungan antara lama sakit dengan tingkat 
distress pada pasien diabetes melitus di Rumah Sakit KRMT Wongsonegoro. Nilai koefisien korelasi bernilai negative $(-0,674)$ yang berarti hubungan lama sakit dengan tingkat distress adalah berlawan, sehingga disimpulkan bahwa terdapat hubungan antara lama sakit dengan tingkat distress pada pasien diabetes melitus di Rumah Sakit KRMT Wongsonegoro, dimana semakin lama sakit maka tingkat distressnya semakin rendah.

Diabetes Melitus (DM) adalah penyakit yang akhir-akhir ini semakin banyak dijumpai. Penyakit ini termasuk jenis penyakit kronis yang tanda awalnya yaitu meningkatnya kadar gula dalam darah sebagai akibat adanya gangguan sistem metabolisme dalam tubuh. Organ tubuh yang terganggu adalah pancreas yang mana sudah tidak berfungsi sebagaimana mestinya. Pankreas sudah tidak mampu memproduksi hormon insulin dalam memenuhi kebutuhan tubuh dimana insulin, yaitu suatu hormon yang diproduksi pankreas, mengendalikan kadar glukosa dalam darah dengan mengatur produksi dan penyimpanannya.

Diabetes Melitus tipe 2 merupakan salah satu tipe dimana terjadi resistensi atau kekurangan insulin yang terjadi akibat dari gangguan sekresi insulin bersama resistensi insulin disertai definisi insulin relatif. Berbeda dengan Diabetes Melitus tipe 1, dimana tidak terjadi destruksi sel beta. Pankreas tetap menghasilkan insulin, kadang kadarnya lebih tinggi dari normal. Tetapi tubuh membentuk kekebalan terhadap efeknya, sehingga terjadi kekurangan insulin relatif. Gejala pada tipe kedua ini terjadi secara perlahan-lahan.

Distress merupakan satu masa terganggunya fungsi manusia yang berkaitan dengan alam perasaan yang sedih dan gejala penyertanya, termasuk perubahan pada pola tidur dan nafsu makan, psikomotor, konsentrasi, anhedonia, kelelahan, rasa putus asa dan tidak berdaya, serta bunuh diri. Faktor penyebab distress terbagi atas faktor biologi, faktor genetik dan faktor psikososial. Ketiga faktor tersebut juga dapat saling mempengaruhi satu sama lain. Namun, yang paling banyak banyak diteliti adalah penyebab dari faktor psikososial. Penyebab distress dari faktor psikososial antara lain dikarenakan peristiwa kehidupan dan stress lingkungan, faktor psikoanalitik dan psikodinamik. Freud dalam (Kaplan, 2010) menyatakan bahwa kemarahn pasien distress diarahkan kepada diri sendiri karena mengidentifikasikan terhadap objek yang hilang. Freud percaya bahwa introjeksi merupakan suatu cara ego untuk melepaskan diri terhadap objek yang hilang. Distress menjadi suatu efek yang dapat melakukan sesuatu terhadap agresi yang diarahkan kedalam dirinya. Apabila pasien distress menyadari bahwa mereka tidak hidup sesuai dengan yang dicita-citakannya, akan mengakibatkan mereka putus asa.

Hubungan lama sakit dengan tingkat distress adalah lama sakit yang dialami pasien maka pasien akan semakin memahami kondisi yang dirasakan baik dari segi fisik, psikologis, hubungan sosial dan lingkungan. Pemahaman yang dialami pasien terhadap sakitnya akan mendorong pasien untuk lebih mampu mengantisipasi munculnya kegawatan atau sesuatu hal yang mungkin terjadi pada diri pasien. Hal ini sebagaimana dikemukakakan oleh Azizah (2011) yang mengemukakan bahwa lama sakit seseorang berdampak pada kemampuan orang tersebut memahami kondisi dirinya dan mengendalikan dirinya terhadap keadaan kesehatannya dan mampu menekan timbulnya kecemasan pasien. 
Tabel 3 Hubungan Lama sakit dengan Depresi penderita Diabetes Mellitus

\begin{tabular}{|c|c|c|c|c|c|c|c|}
\hline \multirow{3}{*}{$\begin{array}{l}\text { Lama } \\
\text { Sakit }\end{array}$} & \multicolumn{6}{|c|}{ Tingkat Depresi } & \multirow[t]{3}{*}{ P Value } \\
\hline & \multicolumn{2}{|c|}{ Ringan } & \multicolumn{2}{|c|}{ Sedang } & \multicolumn{2}{|c|}{ Berat } & \\
\hline & $\mathrm{F}$ & $\%$ & $\mathrm{~F}$ & $\%$ & $\mathrm{f}$ & $\%$ & \\
\hline$<5$ tahun & 6 & 100 & 0 & 0 & 0 & 0 & 0.005 \\
\hline 5-10 tahun & 7 & 54 & 6 & 46 & 0 & 0 & \\
\hline$>10$ tahun & 6 & 46 & 6 & 46 & 1 & 8 & \\
\hline Total & 19 & 60 & 12 & 38 & 1 & 2 & \\
\hline
\end{tabular}

Sumber :data primer 2018

Penelitian ini menunjukkan bahwa hubungan antara lama sakit dengan tingkat distress pada pasien diabetes melitus, dengan Nilai koefisien sebesar 1,427dimana semakin lama sakit maka tingkat distressnya semakin rendah. Hasil penelitian didukung oleh penelitian sebelumnya yang dilakukan oleh Firdaus (2013) yang meneliti hubungan lama menderita DM tipe 2 terhadap tingkat depresi pada pasien poli penyakit dalam
RSD Dr. Soebandi Jember. Penelitian ini menyimpulkan bahwa terdapat hubungan lama menderita Diabetes Melitus Tipe 2 dengan tingkat depresi pada pasien poli penyakit dalam RSD Dr Soebandi Jember. Nilai korelasi Spearman sebesar $-0,543$ menunjukkan bahwa arah korelasi negatif dengan kekuatan sedang, dalam hal ini menunjukkan bahwa semakin lama menderita Diabetes Melitus Tipe 2, maka gejala depresi akan semakin menurun.

Tabel 4 Hubungan adanya ulkus dengan Stress penderita Diabetes Mellitus

\begin{tabular}{llcccccc}
\hline \multirow{2}{*}{ Adanya ulkus } & \multicolumn{3}{c}{ Stress } & \multicolumn{2}{c}{ P value } \\
& \multicolumn{2}{c}{ Ringan } & \multicolumn{2}{c}{ Sedang } & \multicolumn{2}{c}{ Berat } & \\
\cline { 2 - 7 } & F & $\%$ & F & $\%$ & $\mathrm{f}$ & $\%$ & 0.003 \\
\hline
\end{tabular}

Sumber :data primer 2018

Hasil Analisis menunjukkan adanya $\mathrm{p}$ value 0,003 . Handoko dalam Lukaningsih (2011) menjelaskan bahwa stres merupakan suatu ketegangan yang dapat mempengaruhi emosi, proses berpikir dan kondisi berpikir seseorang. Stres pada diri seseorang dapat dipicu oleh beberapa hal. Salah satu dari pemicu stres pada diri seseorang adalah kondisi biologis, berbagai penyakit infeksi, trauma fisik dengan kerusakan organ biologis, malnutrisi, kelelahan fisik. Hal ini didukung oleh penelitian dari Sofiana (2012) tentang Hubungan Antara Stres Dengan Konsep Diri Pada Penderita
Diabetes Mellitus Tipe 2 yang menyatakan konsep diri responden yang mengalami DM tipe 2.

Stres memiliki beberapa tahapan, mulai tahap 1 hingga tahap ke 6 . Stres tahap kedua, yaitu stres yang disertai keluhan, seperti bangun pagi tidak segar atau letih, lekas capek pada saat menjelang sore, lekas lelah sesudah makan, tidak dapat rileks, lambung atau perut tidak nyaman, jantung berdebar, otot tengkuk, dan punggung tegang, hal tersebut karena cadangan makanan tidak memadai (Hawari, 2010). 
Tabel 5 Hubungan adanya ulkus dengan Depresi penderita Diabetes Mellitus

\begin{tabular}{|c|c|c|c|c|c|c|c|}
\hline \multirow[t]{3}{*}{ Adanya ulkus } & \multicolumn{6}{|c|}{ Tingkat depresi } & \multirow[t]{2}{*}{$P$ value } \\
\hline & & & & lang & & rat & \\
\hline & $\mathrm{F}$ & $\%$ & F & $\%$ & f & $\%$ & \\
\hline ada & 19 & 60 & 12 & 38 & 1 & 2 & 0.001 \\
\hline
\end{tabular}

Penderita yang mengalami DM sangat berisiko terjadinya ulkus atau gangren serta berisiko untuk dilakukan amputasi, sehingga timbul perasaan takut terhadap tidak adanya penerimaan dan penolakan interpersonal. Komplikasi Hasil penelitian ini sejalan dengan Wirnata, (2009) pandangan interpersonal mengatakan bahwa cemas timbul dari perasaan takut terhadap tidak adanya penerimaan dan penolakan interpersonal. Depresi juga berhubungan dengan perkembangan trauma seperti perpisahan dan kehilangan yang menimbulkan kelemahan spesifik.

\section{SIMPULAN}

Terdapat hubungan antara lama sakit dengan tingkat distress pada pasien diabetes mellitus di RSUD K.R.M.T Wongsonegoro ( $p$-value $=0,001)$ dimana semakin lama sakit, maka tingkat distress semakin rendah.

\section{SARAN}

Bagi tenaga kesehatan hasil penelitian ini dapat menjadi acuan khususnya tentang faktor- faktor yang berhubungan dengan stress dan depresi pasien diabetes mellitus. Pengetahuan perawat terhadap factor-faktor yang mempengaruhi stress dan depresi pasien diabetes mellitus berguna dalam meningkatkan kemampuan perawat untuk memberikan asuhan keperawatan yang dapat menekan tingkat stress dan depresi pasien. Untuk peneliti selanjutnya yang ingin meneliti dengan tema yang sama diharapkan meningkatkan jumlah responden serta menambahkan factor-faktor yang berhubungan dengan tingkat distress dan depresi pasien DM misalnya pengetahuan, sikap, dukungan keluarga, dukungan social dan lain sebagainya, sehingga diketahui faktor apakah yang paling dominant berhubungan dengan tingkat distress dan depresi pasien DM.

\section{DAFTAR PUSTAKA}

Azizah L.M. 2011. Keperawatan Jiwa (Aplikasi Praktik Klinik).Graha Ilmu: Yogyakarta.

Damayanti dan Ayu. (2015). Pengaruh Pendidikan Kesehatan Terhadap Tingkat pengetahuan Pasien Diabetes Melitus Tipe 2 Dalam Pencegahan Ulkus Kaku Diabetik Di Poliklinik RSUD Panembahan Senopati Bantul,Vol 2, No 1

Firdaus, A (2013). Hubungan Lama Menderita DM tipe 2 Terhadap Tingkat Depresi pada Pasien Poli Penyakit Dalam RSD Dr. Soebandi Jember. Jurnal Kedokteran. No. 3 Vol. 3. Jember: Fakultas Kedokteran Universitas Jember.

Ferawati, Ira., 2014, Faktor-Faktor yang Mempengaruhi Terjadinya Ulkus Diabetikum pada Pasien DM Tipe 2 di RSUD Prof. Dr. Margono Soekarjo, skripsi, Ilmu Keperawatan Universitas Jenderal Soedirman, Purwokerto.

Galveia, Cruz \& Deep (2012). The Depression Anxiety Stress Scales (DASS).Normative Data and Latent Structure in Large Non Clinical Sample. British Journal of Clonical Psycology.

Hastuti, RT. Faktor-faktor risiko ulkus diabetika pada Penderita DM. Tesis. Semarang. Universitas Diponorogo. 2008 
Hawari, D., 2010. Psikologi Keperawatan. Jakarta : EGC

Irawan, Dedi. 2010. Prevalensi dan Faktor Risiko Kejadian Diabetes Melitus Tipe 2 di Daerah Urban Indonesia (Analisa Data Sekunder Riskesdas 2007). Thesis Universitas Indonesia

Jelantik IMG. (2014). Hubungan Faktor Risiko Umur, Jenis Kelamin, Kegemukan dan Hipertensi dengan Kejadian Diabetes Mellitus Tipe II di Wilayah Kerja Puskesmas Mataram. Media Bina Ilmiah. Vol I, No. 2.

Kaplan, H.I., Sadock, B.J. 2010. Retardasi Mental dalam Sinopsis Psikiatri. Tangerang : Binarupa Aksara

Kekenusa J. 2013. Analisis hubunganantara umur dan riwayat keluarga menderita Diabetes Mellitus Dengan Kejadian Diabetes Mellitus Tipe 2 pada pasien rawat jalan di Poliklinik Penyakit Dalam BLU RSUP Prof. Dr. R.D. Kandou Manado. Jurnal Kesehatan. Manado: UniversitasSam Ratulangi

Notoatmodjo, S. 2012. Metodologi Penelitian Kesehatan. Jakarta: Rineka Cipta

Perry \&Potter, 2005. Buku Ajar Fundamental Keperawatan, Konsep, Proses dan Praktik. Jakarta: EGC

Suyono, 2007. Diabetes Mellitus di Indonesia. Buku Ajar Ilmu Penyakit Dalam. IV. Ed. Jakarta: Pusat Penerbitan Ilmu Penyakit Dalam FKUI.

Sunjaya, I Nyoman. 2009. Pola Konsumsi Makanan Tradisional Bali Sebagai Faktor Resiko DM Tipe II di Tabanan. Jurnal skala Husada vol.6 No. 1 hal:7581

Soegondo S., 2009. Farmakoterapi pada Pengendalian Glikemia Diabetes Melitus tipe II. Buku Ajar Ilmu Penyakit Dalam. Jilid III. Edisi V. Jakarta: Interna Publishing. Hal 18841886
Suyono, 2007. Diabetes Mellitus di Indonesia. Buku Ajar Ilmu Penyakit Dalam. IV. Ed. Jakarta: Pusat Penerbitan Ilmu Penyakit Dalam FKUI.

Setyani, T. 2012. Hubungan Tingkat Depresi dengan Kadar Gula Darah pada Penderita Diabetes Mellitus tipe 2 di RSUD Karanganyar [skripsi] Surakarta: Universitas Muhammadiyah Surakarta.

Smeltzer,S.C.,\&Bare,B.G. (2013). Buku Ajar Keperawatan Medikal Bedah Brunner \& Suddarth (8th ed) (H.Y Kuncara, dkk, penerjemah). Jakarta : EGC

Sofiana, Elita.V., Utomo.W. (2012). Hubungan Antara Stres Dengan Konsep Diri Pada Penderita Diabetes Melitus Tipe 2. Jurnal STIKES Muhammadiyah Riau Program Studi Ilmu Keperawatan. Diakses pada tanggal 2 Maret 2012.

Tjandra, H., 2008. Segala Sesuatu Yang Harus Anda Ketahui Tentang DIABETES: Panduan lengkap Mengenal dan Mengatasi Diabetes dengan Cepat danMudah. Jakarta: PT Gramedia Pustaka Utama.

Trisnawati., Kurnia.,\& Setyorogo (2013). Faktor Risiko Kejadian Diabetes Tipe II di Puskesmas Kecamatan Cengkareng Jakarta Barat Tahun 2012. Jurnal Ilmiah Kesehatan. Vol 5 No. 1. Jakarta: Program Studi S1 Kesehatan Masyarakat STIKES Muh. Tamrin

Wirnata M. 2009. Keperawatan dan Kesehatan Jiwa, (online): available: http://www.Infosehat.com/2009/05/kece masan-pada-penyakit-dm.html (2012,April 02). 